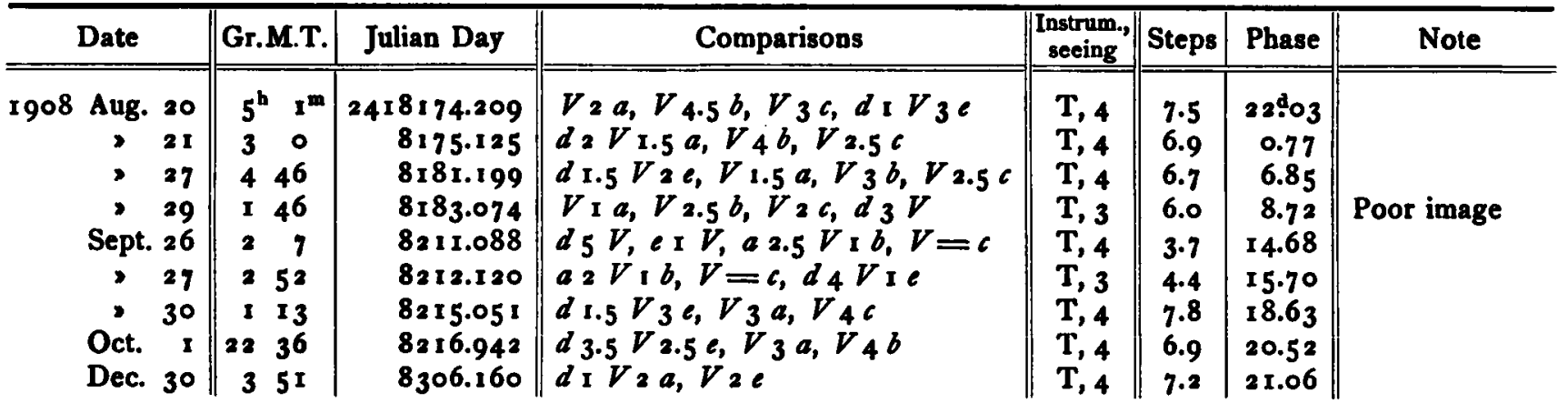

At first, I took as basis for the investigation the provisional period derived by Blažko and calculated the phases of all the observations. Then the graphical process showed that this value of the period is a little too long to represent my observations well. Thus, balancing the residuals, I obtained a value $22^{d} \times 7$ better suited. I tried also 22.14 but the result seems rather worse than that depending upon $22 \mathrm{~d} .7$. Therefore this value $22 \mathrm{~d} 7 \mathrm{f}$ was taken as the period and 2417620 . 0 as the initial epoch. The phases of the observations calculated according to these elements are shown in the above table. Then rearranging the brightness in the order of the phase, I found that the observations agree well in the increasing branch of the light-curve, while the other branch does not agree so well. Besides this, the observations made here show the minimum brighter than the observations made at the Yerkes Observatory. But being at present unable to ascertain whether this is due to the instrument or not, I took both series of observations without distinction. Now grouping the observations according to the phase and combining always five observations following one another we get:

$\begin{array}{rccc}\text { Phase } & \text { Steps } & \text { Phase } & \text { Steps } \\ \text { Od.46 } & \mathbf{7 . 2} & \text { I 3.67 } & \mathbf{3 . 1} \\ \mathbf{2 . 6 2} & 6.5 & 15.53 & 3.3 \\ 4.38 & 6.8 & 16.20 & 3.8 \\ 6.69 & 6.7 & 17.52 & 5.7 \\ 8.29 & 4.4 & 18.74 & 7.0 \\ 9.99 & 3.3 & 19.88 & 7.2 \\ 11.42 & 1.8 & 21.22 & 7.8\end{array}$

These values were plotted on a sectioned-paper as usual, taking the brightness as the ordinate and the phase

Tokyo Astronomical Observatory, x908 Dec. 31 .

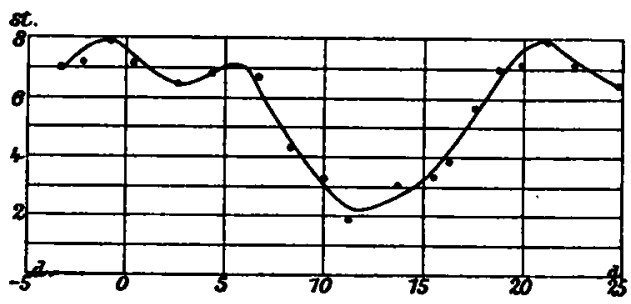

as the abscissa, and a smooth curve was drawn through or near to these plotted points as shown in the above figure. The mean curve shows a secondary maximum and the general nature of the curve resembles that of S Sagittae. The principal maximum, 7.8 steps, occurs at the phase one day earlier than the initial epoch, and the secondary, of $7^{\text {st }} 1$, occurs at the phase $5: 3$. The principal minimum is attained at the phase 11.8 and is of 2.3 steps, while the secondary minimum takes place at the phase $3 \%$ and reaches 6.5 steps. The range of variation, therefore, is $6^{\mathrm{st}} .5$ according to my step-magnitude. Then the formula for maximum will be as follows :

$$
\begin{gathered}
\text { Max. }=24 \text { I } 76 \text { I } 9 \stackrel{d}{\circ} \text { Gr. M. T. }+22 \stackrel{d}{1} 7 E . \\
M-m=9: 4 .
\end{gathered}
$$

As already stated, I tried to get the mean curve of my observations with the value 22.14 of the period, since this, or more precisely 22.139 , seems to satisfy the earlier observations which Prof. Kreutz collected. In this sense 22 . 139 may be the mean period in the long interval covering nearly I I 00 periods but $I$ think the value $22 \mathrm{~d} 17$ is more suitable in the interval over which my observations extend.

\section{Naozo Ichinohe.}

\title{
Genäherte Elemente für zwei neue Algolsterne.
}

13.1908 Lacertar. Aus den I 2 beobachteten Minima I 908 Sept. 4 und 24, Okt. 2 2, Nov. 19 und 29, Dez. 4, 12 und 27, 1909 Jan. I 9 und 24, Febr. 21 und 26, Mărz 13 sind die folgenden genäherten Elemente abgeleitet:

Min. $=1909$ Jan. $195^{\text {h }}$ M. Z. Gr. $+2^{d} 1_{2^{h}}^{\text {h }} 5^{\text {m }} \cdot 7 E$

$$
=2418326.21 \text {, }+2{ }^{d} 5366 E \text {. }
$$

48.1908 Tauri. Im Zeitraum I908 Okt. I9 bis I909 Mărz 18 ist der Stern an $6 r$ Tagen in derselben Helligkeit

Dombaas, 1909 Mărz 19. beobachtet. An den folgenden Tagen war seine Lichtstärke etwa eine Größenklasse schwächer:

r 909 Jan. 9 und 25 , Febr. 20 und März 18.

Genßherte Elemente :

$$
\begin{aligned}
\text { Min. }= & 1909 \text { Jan. } 257^{\mathrm{h}} \text { M. Z. Gr. } \\
= & +5^{\mathrm{d}} 5^{\mathrm{h}} \cdot 5 E \\
& =2418332.29
\end{aligned}
$$

Eine kürzere Periode ist nicht ganz ausgeschlossen. 